
\title{
25 Research Square \\ Effect of Aftershock Characteristics on the Fragility Curve of Post-Mainshock RC Frames
}

\author{
Ali Massumi ( $\nabla$ ali.massumi@gmail.com ) \\ Kharazmi University https://orcid.org/0000-0003-4636-6553 \\ Kabir Sadeghi \\ Near East University: Yakin Dogu Universitesi \\ Omid Ghojoghi \\ Kharazmi University
}

\section{Research Article}

Keywords: fragility curves, aftershocks, probability of collapse, reinforced concrete structures

Posted Date: June 7th, 2021

DOI: https://doi.org/10.21203/rs.3.rs-597714/v1

License: (1) This work is licensed under a Creative Commons Attribution 4.0 International License. Read Full License 


\section{Abstract}

Buildings constructed in seismic zones are not only damaged by mainshocks but may also be damaged by the impact of aftershocks and cause them to collapse. Therefore, studying the behavior of the damaged structures due to the mainshock and aftershock helps in post-mainshock decision making and also in the selection of suitable aftershock records for seismic assessing of the structure under earthquake sequences. This paper presents the effects of aftershock ground motion on the collapse capacity of post-mainshock buildings. The mean period $\left(T_{m}\right)$, predominant velocity period $\left(T_{g}\right)$, frequency bandwidth $(\Omega)$, the $5 \%-95 \%$ significant duration $\left(D_{s}\right)$ and seismic records of different sites were selected to evaluate the effect of its characteristics on the collapse capacity of buildings. The intensity of the ground motions was determined by the first-mode spectral acceleration with $5 \%$ damping. Collapse capacities of two non-ductile reinforced concrete (RC) frames with 3 and 6 stories were evaluated using a set of 62 aftershock records with a wide range of characteristics. Box plot collapse diagrams and fragility curves have been developed by applying the incremental dynamic analysis (IDA). The results show that in the frequency content with a longer period, the probability of its collapse is higher. In addition, the high significant duration of aftershocks increases the collapse probability of structures. Also, the evaluation of the site characteristics shows differences in collapse capacities of the same frames in varying sites. Therefore, the effect of aftershock characteristics on the capacity of the structures is significant and it is necessary to carefully determine the seismic sequences' recordings for the evaluation of the seismic behavior of the structures.

\section{Introduction}

One of the important aspects of seismic analysis of structures is the development of fragility curves to determine the probability of structural failure at different earthquake intensities. Fragile relationships are important inputs of the software applied to economic damage assessment. These relationships are useful in understanding the levels of damage to a structure under a range of earthquake intensities. This has made fragility curves an important tool in the seismic evaluation of reinforced concrete (RC) structures (Abdelnaby, 2018).

Ryu et al. (2011) proposed a method to develop the fragility curve of damaged structures due to mainshock seismic damage using seismic sequencing and incremental dynamic analysis (IDA) (Ryu et al., 2011). They developed the collapse fragility curves for a 5-story ordinary RC moment-resisting frame (MRF) located in New Zealand, in both the intact and damaged states. In this method, great conceptual improvements have been made compared to the similar method used in the research of Ryu et al. (2011). The proposed method is capable of considering uncertainties in seismic response. It also has the ability to take into account uncertainty about the extent of the damage when attaining the aftershock fragility curve.

Jeon et al. (2012) proposed an analytical procedure to create aftershock fragility curves for a three-story and three-span RC structure designed for a gravitational load combination (Jeon et al., 2012). To assess 
the increasing damage, they developed a valid analytical model in OpenSees software. They carried out pushover and time-history analyses for the intended analytical and possibility models. Besides, they obtained the aftershock fragility curves with different initial damage states. By using it, they verified that the more initial damage experienced by the structure, the higher seismic demand observed when applying the same aftershocks.

Raghunandan et al. (2015) analyzed analytical models of modern RC buildings. They exposed these models to two identical records of earthquake movements (Raghunandan et al., 2015). They performed the analysis in such a way that the response and the structural damage were first recorded in the main record. Then the damaged structure is exposed to the next ground movement by the mainshock which its intensity increases by applying the IDA until the structure collapse. Their results showed that the fragility of the structure subjected to the aftershock was significantly increased for structures damaged in the mainshock. Their results also showed that the lesser damage caused by the mainshock, the lesser impact of the aftershock on the fragility of the building.

Hosseinpour and Abdelnaby (2017) evaluated the fragility curve of RC frames under the recorded seismic sequences. They evaluated various parameters including damage caused by the mainshock, the vertical component of earthquake, earthquake zone, number of stories and earthquake intensity on the fragility curves (Hosseinpour \& Abdelnaby, 2017). They concluded that by applying aftershocks to non-damaged structures, small structural damages are observed at different yield states. According to their research, this observation may be due to the shorter duration of time and the shorter frequency range of aftershocks. They also observed that the differences in fragility curves in the four defined limit states decrease with increasing the number of stories, which may be due to the movement of upper stories in tall buildings under an identical vibration. Besides, they observed that the vertical component of the earthquake did not have a significant impact on the fragility curves prepared based on the maximum drift. They concluded that using maximum ground acceleration as an earthquake intensity gives appropriate results for three-story buildings. But with the increase in the number of the stories, the use of this intensity does not seem appropriate to obtain the fragility curves. While spectral acceleration works well for all buildings. According to their results, the structural damage increases as the number of stories increases. They also observed the significant impacts of the earthquake zone and the earthquake characteristics on the fragility curves.

\section{Aftershock Properties}

Due to differences in the mechanism of the mainshock and aftershock, the characteristics of the mainshock may be significantly different from those associated with the aftershocks. Therefore, to ensure accurate evaluation of seismic behavior of structures, the aftershock hazard and its characteristics must be considered. The characteristics of the ground motion have a significant impact on the seismic behavior of buildings, including the intensity of the ground movement, spectral shape, duration, frequency content and other characteristics. In order to predict accurately the behavior of 
structures and minimize the dispersion of their analytical behavior, it is necessary to consider the characteristics of the record in the procedure of selecting the ground motion records (Song et al., 2014).

Although the significant impact of the earth movement duration on soil liquefaction and slope instability is known (Bray, 2007; Green \& Terri, 2005), the impact of the earth movement duration on the structural response still needs further investigation (Bommer et al., 2006). The degree of the impact of duration depends on many factors, including the definition of duration, seismic demand parameters, failure criteria, and nonlinear structural characteristics (Hancock \& Bommer, 2006). Experimental results of steel and RC frames showed that the duration of the ground movement or the number of loading periods are directly related to the damage to the structures. The damage to the joints of the steel MRFs observed in the Northridge and Kobe earthquakes was due to fatigue during short loading periods. This indicates that the duration of the earth's movement has a significant impact on the seismic behavior of the structure (Bommer et al., 2006). The analytical studies using cumulative damage measurements have found a direct relationship between duration and damage to structures. But when the failure criteria for maximum response are used, some analytical studies have found a weak relationship between duration and failure, unless the structural redundancy features and the load redistribution are taken into account (Raghunandan \& Liel, 2013).

The frequency content of the earth movement may have a significant impact on the dynamic response of buildings that are subjected to an earthquake. When the frequency content of ground movements approaches the fundamental periods of buildings, the dynamic response of structures and seismic forces can be effectively increased and the buildings experience severe damage. From an engineering perspective, it is better to determine the frequency content using a scalar parameter rather than a spectral response to provide comprehensive information on the frequency content of the ground motion (Song et al., 2014).

Previous studies have proposed several scalar parameters of frequency content to investigate their effects on the seismic behavior of buildings. These include the predominant velocity period $(\mathrm{Tg})$, the characteristic period $\left(T_{c}\right)$ and the mean period $\left(T_{m}\right)$. The dominant velocity period represents the maximum relative velocity spectrum period with damping of $5 \%$ for an elastic system with a single degree of freedom (SDOF) (Song et al., 2014). Some researchers have used the predominant velocity period to specify the seismic demand of buildings (Uang \& Maarouf, 1994), (Ruiz-García \& Miranda, 2004), (Chakraborti \& Gupta, 2005). Ruiz-García investigated the characteristics of mainshock-aftershock (Ruiz-García, 2012). He described the shortness of the predominant velocity period of aftershocks than the mainshock and the probability of its significant impact on the seismic behavior of the damaged structures.

The characteristic period is related to the interaction width of the two straight lines, which illustrates the ideal acceleration response spectrum. 
The mean period is defined as the mean Fourier amplitude spectra over a specified frequency range (Song et al., 2014). Rathje et al. (1998) suggested the use of the mean period because of its relation to the Fourier spectra and its high performance in detecting the frequency content of strong earthquake movements (Rathje et al., 1998). Kumar et al. (2011) showed that the seismic drift of SDOF systems increases if the fundamental period $\left(T_{1}\right)$ to $T_{m}$ ratio is less than one (Kumar et al., 2011). Besides, the base shear and maximum shear drift in multi-degree of freedom (MDOF) systems significantly are affected by the higher modes when $T_{m}$ reaches the higher modes in the building. Kumar et al. (2013) found that the $T_{1}$ to $T_{m}$ ratio and the coefficient of behavior have a significant impact on the overall building drift (Kumar et al., 2013). Song et al. (2014) also investigated the effect of the mean period and aftershock duration on the collapse capacity of SDOF and MDOF steel structures with different damage levels (Song et al., 2014).

\section{Modeling}

Numerical analysis using appropriate software is needed to develop the fragility curve and other graphs. To do this, appropriate ground movement records for use in the dynamic time-history analysis is needed to be applied. The building is modelled for investigation in a software environment whose nonlinear behavior has been verified by experimental results and numerical analysis. In this paper, the stages of analysis required to develop the curves of fragility are outlined.

Mainshock-aftershock database

To investigate the characteristics of mainshock and aftershocks, the database of the Pacific Earthquake Engineering Research was used to determine the acceleration time-history of the recorded mainshock and aftershocks. The following criteria are used to select the mainshock and aftershocks:

1) The magnitude of at least 5 on the Richter scale for the mainshock and aftershocks, which has the potential to cause damage to buildings;

2) Peak ground acceleration (PGA) of the horizontal components of the mainshock and aftershocks are more than 0.05 of the gravitational acceleration, which can cause damage without applying excessive scales to the intensity of the earth's motion.

3) Only the far-field ground movements without large pulses in velocity time-history are selected to avoid near-field effects or fault orientation, and

4) The acceleration sensors are installed in open areas or low-rise buildings to neglect the soil-structure interference (Song et al., 2014).

According to the criteria mentioned in the earth movement record selection, 62 seismic records used in the work of Song et al. (2014) from 9 seismic events in the California, Italy, and Chichi of Taiwan sites are selected to explore the impact of aftershock characteristics on the capacity of the collapse of the structures damaged due to the mainshock. The magnitudes of the aftershock characteristics are specified in Table 1 (Song et al., 2014). Details of the selected aftershock records are also given in Table 2.

Table 1. The magnitudes of the aftershock characteristics

\begin{tabular}{|l|c|c|c|c|}
\hline $\begin{array}{l}\text { Aftershock } \\
\text { characteristics }\end{array}$ & $\begin{array}{c}\text { Mean period, } \\
\operatorname{Tm} \text { (sec.) }\end{array}$ & $\begin{array}{c}\text { Predominant velocity } \\
\text { period, } \mathrm{T}_{\mathrm{g}} \text { (sec.) }\end{array}$ & $\begin{array}{c}\text { Frequency } \\
\text { bandwidth, } \Omega\end{array}$ & $\begin{array}{c}\text { Significant duration, } \\
\text { Ds (sec.) }\end{array}$ \\
\hline Minimum & 0.19 & 0.2 & 0.27 & $\mathbf{0 2 . 2 7}$ \\
\hline Maximum & 1.35 & 4.0 & 0.64 & $\mathbf{4 1 . 8 6}$ \\
\hline
\end{tabular}


Table 2. Details of the selected aftershock records (Song et al., 2014) 


\begin{tabular}{|c|c|c|c|c|c|}
\hline Earthquake & ID. & $\begin{array}{c}\text { Significant } \\
\text { duration, Ds (sec.) }\end{array}$ & $\begin{array}{l}\text { Mean period, } \\
\text { Tm (sec.) }\end{array}$ & $\begin{array}{l}\text { Predominant velocity } \\
\text { period, } \mathrm{T}_{\mathrm{g}} \text { (sec.) }\end{array}$ & $\begin{array}{c}\text { Frequency } \\
\text { bandwidth, } \Omega\end{array}$ \\
\hline $\begin{array}{l}\text { Whittier } \\
\text { Narrows }\end{array}$ & NGA714 & 06.15 & 0.34 & 0.68 & 0.502827 \\
\hline $\begin{array}{l}\text { Whittier } \\
\text { Narrows }\end{array}$ & NGA714 & 05.17 & 0.24 & 0.26 & 0.560216 \\
\hline $\begin{array}{l}\text { Whittier } \\
\text { Narrows }\end{array}$ & NGA709 & 12.30 & 0.44 & 0.52 & 0.571857 \\
\hline $\begin{array}{l}\text { Whittier } \\
\text { Narrows }\end{array}$ & NGA711 & 10.84 & 0.47 & 0.74 & 0.465577 \\
\hline Northridge & NGA1730 & 07.98 & 0.24 & 0.58 & 0.569246 \\
\hline Northridge & NGA1733 & 03.71 & 0.32 & 0.58 & 0.586999 \\
\hline Northridge & NGA1723 & 07.44 & 0.40 & 0.68 & 0.614331 \\
\hline Northridge & NGA1732 & 02.38 & 0 & 0.32 & 0.642762 \\
\hline Northridge & NGA1706 & 14.90 & 0.31 & 0.54 & 0.581909 \\
\hline Northridge & NGA1683 & 09.04 & 0.38 & 0.32 & 0.562500 \\
\hline Northridge & NGA1676 & 09.66 & 0.60 & 0.82 & 0.536827 \\
\hline Northridge & NGA1676 & 08.12 & 0.47 & 0.42 & 0.612033 \\
\hline $\begin{array}{l}\text { Mammoth } \\
\text { lakes }\end{array}$ & NGA235 & 03.28 & 0.22 & 0.22 & 0.605839 \\
\hline $\begin{array}{l}\text { Mammoth } \\
\text { lakes }\end{array}$ & NGA234 & 10.28 & 0.47 & 0.70 & 0.578584 \\
\hline $\begin{array}{l}\text { Mammoth } \\
\text { lakes }\end{array}$ & NGA320 & 07.14 & 0.56 & 0.60 & 0.546964 \\
\hline $\begin{array}{l}\text { Mammoth } \\
\text { lakes }\end{array}$ & NGA239 & 07.76 & 0.36 & 0.50 & 0.603953 \\
\hline $\begin{array}{l}\text { Mammoth } \\
\text { lakes }\end{array}$ & NGA236 & 06.30 & 0.47 & 0.52 & 0.471227 \\
\hline Livermore & NGA224 & 19.05 & 0.53 & 0.44 & 0.538949 \\
\hline Livermore & NGA222 & 04.50 & 0.28 & 0.20 & 0.517946 \\
\hline Livermore & NGA221 & 03.23 & 0.39 & 0.50 & 0.599275 \\
\hline Livermore & NGA223 & 12.43 & 0.53 & 0.74 & 0.562609 \\
\hline Livermore & NGA223 & 05.63 & 0.59 & 0.76 & 0.546796 \\
\hline $\begin{array}{l}\text { Irpinia, } \\
\text { Italy }\end{array}$ & NGA302 & 22.95 & 0.54 & 1.24 & 0.502817 \\
\hline $\begin{array}{l}\text { Irpinia, } \\
\text { Italy }\end{array}$ & NGA302 & 20.93 & 0.66 & 1.60 & 0.408777 \\
\hline $\begin{array}{l}\text { Irpinia, } \\
\text { Italy }\end{array}$ & NGA303 & 13.63 & 0.43 & 0.56 & 0.553178 \\
\hline $\begin{array}{l}\text { Irpinia, } \\
\text { Italy }\end{array}$ & NGA300 & 20.01 & 0.84 & 1.52 & 0.391146 \\
\hline $\begin{array}{l}\text { Irpinia, } \\
\text { Italy }\end{array}$ & NGA300 & 18.10 & 0.90 & 1.20 & 0.408461 \\
\hline $\begin{array}{l}\text { Irpinia, } \\
\text { Italy }\end{array}$ & NGA297 & 22.02 & 1.26 & 4.00 & 0.398200 \\
\hline $\begin{array}{l}\text { Irpinia, } \\
\text { Italy }\end{array}$ & NGA297 & 21.00 & 1.07 & 1.90 & 0.391859 \\
\hline
\end{tabular}




\begin{tabular}{|c|c|c|c|c|c|}
\hline $\begin{array}{l}\text { Imperial } \\
\text { Valley }\end{array}$ & NGA208 & 05.74 & 0.58 & 0.66 & 0.496751 \\
\hline $\begin{array}{l}\text { Imperial } \\
\text { Valley }\end{array}$ & NGA204 & 06.54 & 0.41 & 0.76 & 0.532418 \\
\hline $\begin{array}{l}\text { Imperial } \\
\text { Valley }\end{array}$ & NGA200 & 02.76 & 0.45 & 0.52 & 0.544118 \\
\hline $\begin{array}{l}\text { Imperial } \\
\text { Valley }\end{array}$ & NGA196 & 11.18 & 0.25 & 0.88 & 0.562522 \\
\hline $\begin{array}{l}\text { Imperial } \\
\text { Valley }\end{array}$ & NGA193 & 09.81 & 0.59 & 0.80 & 0.477699 \\
\hline $\begin{array}{l}\text { Imperial } \\
\text { Valley }\end{array}$ & NGA193 & 12.36 & 0.36 & 0.58 & 0.545063 \\
\hline Friuli, Italy & NGA133 & 05.02 & 0.40 & 0.26 & 0.416267 \\
\hline Friuli, Italy & NGA132 & 04.58 & 0.31 & 0.38 & 0.532884 \\
\hline Friuli, Italy & NGA132 & 04.50 & 0.26 & 0.40 & 0.587593 \\
\hline Friuli, Italy & NGA130 & 10.24 & 0.60 & 0.82 & 0.493841 \\
\hline Friuli, Italy & NGA130 & 08.14 & 0.71 & 1.72 & 0.418835 \\
\hline Coalinga & NGA409 & 08.04 & 0.45 & 1.06 & 0.502895 \\
\hline Coalinga & NGA414 & 10.43 & 0.30 & 0.30 & 0.546269 \\
\hline Coalinga & NGA414 & 10.42 & 0.30 & 1.08 & 0.524517 \\
\hline Coalinga & NGA406 & 06.19 & 0.27 & 0.44 & 0.502378 \\
\hline Coalinga & NGA392 & 16.08 & 0.76 & 3.14 & 0.398881 \\
\hline Coalinga & NGA391 & 14.80 & 0.48 & 0.36 & 0.551423 \\
\hline Coalinga & NGA384 & 02.27 & 0.19 & 0.26 & 0.609423 \\
\hline Coalinga & NGA375 & 05.18 & 0.34 & 0.34 & 0.628607 \\
\hline $\begin{array}{l}\text { Chichi, } \\
\text { Taiwan }\end{array}$ & NGA3500 & 41.87 & 0.90 & 2.24 & 0.310927 \\
\hline $\begin{array}{l}\text { Chichi, } \\
\text { Taiwan }\end{array}$ & NGA3474 & 03.96 & 0.38 & 0.48 & 0.594461 \\
\hline $\begin{array}{l}\text { Chichi, } \\
\text { Taiwan }\end{array}$ & NGA3306 & 28.00 & 0.56 & 0.58 & 0.570862 \\
\hline $\begin{array}{l}\text { Chichi, } \\
\text { Taiwan }\end{array}$ & NGA3302 & 38.14 & 0.81 & 3.18 & 0.422610 \\
\hline $\begin{array}{l}\text { Chichi, } \\
\text { Taiwan }\end{array}$ & NGA3302 & 41.06 & 0.77 & 3.62 & 0.351256 \\
\hline $\begin{array}{l}\text { Chichi, } \\
\text { Taiwan }\end{array}$ & NGA3270 & 28.68 & 1.35 & 2.58 & 0.273005 \\
\hline $\begin{array}{l}\text { Chichi, } \\
\text { Taiwan }\end{array}$ & NGA3270 & 27.13 & 0.90 & 2.64 & 0.357903 \\
\hline $\begin{array}{l}\text { Chichi, } \\
\text { Taiwan }\end{array}$ & NGA3267 & 29.84 & 0.54 & 0.60 & 0.551797 \\
\hline $\begin{array}{l}\text { Chichi, } \\
\text { Taiwan }\end{array}$ & NGA2711 & 32.64 & 1.13 & 2.28 & 0.326264 \\
\hline $\begin{array}{l}\text { Chichi, } \\
\text { Taiwan }\end{array}$ & NGA2711 & 32.64 & 0.84 & 3.02 & 0.393672 \\
\hline $\begin{array}{l}\text { Chichi, } \\
\text { Taiwan } \\
\end{array}$ & NGA2646 & 22.98 & 0.82 & 2.42 & 0.369647 \\
\hline $\begin{array}{l}\text { Chichi, } \\
\text { Taiwan }\end{array}$ & NGA2646 & 19.68 & 0.68 & 0.58 & 0.471011 \\
\hline
\end{tabular}




\begin{tabular}{|l|c|c|c|c|c|}
$\begin{array}{l}\text { Chichi, } \\
\text { Taiwan }\end{array}$ & NGA2623 & 07.72 & 0.42 & 0.44 & $\mathbf{0 . 6 1 4 0 9 3}$ \\
\hline $\begin{array}{l}\text { Chichi, } \\
\text { Taiwan }\end{array}$ & NGA2618 & 12.96 & 0.88 & 1.14 & $\mathbf{0 . 4 7 0 5 3 0}$ \\
\hline
\end{tabular}

Specifications of the selected non-ductile RC structures

In this study, two non-ductile RC building frames located in the United States are considered. The 3-span 3story (low-rise) and 3-span 6-story (medium-rise) structures are selected. Figs. 1 and 2 show the detail of the 6story building. These building specimens are one of the most commonly used pre-1975 as RC frames in the United States. These buildings are vulnerable to seismic loads due to their non-seismic design details, inadequate transverse reinforcement, weak columns, short overlapping lengths of reinforcements and poor beam-column joints. Both buildings have the same plan of symmetry in each story and the details of the reinforcement in each story are the same. The columns of the 3-story building and the columns of the 4 to 6 stories of the 6-story building are the same. The fundamental periods of the 3-story and 6-story buildings are 1.14 and 1.92 seconds, respectively. The most common method to estimate the fundamental period of a building is from empirical relations, considering building specification (structure type) and its height from the base level. The fundamental period of buildings may be calculated using analytical methods; in which case, the specified value shall not exceed 1.25 times the period obtained by empirical relation (Imashi \& Massumi, 2011). The compressive strength of the concrete in both buildings was $28 \mathrm{MPa}$ and the yield strength of the reinforcements was $280 \mathrm{MPa}$. A distributed gravitation loading of 40,000 N/m has been applied to the beam spans. A dynamic mass of $15700 \mathrm{~N} / \mathrm{ms}^{2}$ is considered as a node at the junction of beams and columns based on a DL + 0.25LL load combination (Han et al., 2015).

Specifications of the selected non-ductile RC structure

To evaluate the vulnerability of non-ductile RC frames, a numerical model has been developed to simulate the responses of the frames. Previous studies on the effect of different types of structural component responses on overall frame instability are investigated (Jeon et al., 2015a). In these studies, the responses of the old frames have been simulated using a series of different model systems, some of which have been simulated as the nonlinear shear of beam-column joint, the bond stress response and nonlinear shear response of the columns. The results of the analysis showed that the shear response of the joints controls the system response. Even when considering the nonlinear shear response of the column in the model and simulating both the shear failure behavior of the column and the joints, the joints' resistance controls the system response. Besides, the column shear demand has not exceeded the capacity and the shear failure has not been observed (Jeon et al, 2015b). Therefore, a model of the frame in which the nonlinear shear response of the joint (and not the column) is simulated and employed in this study. This model is modelled in OpenSees software and validated by comparing the available analytical and laboratory test results. Braccy et al. (1995) designed and built the 3-story, 3-span RC frame employed in the present study at a one-third scale (Bracci et al., 1995). This frame was designed for testing by the vibrating desk at the University of Buffalo, New York. The earth movement input applied to this structure is the N21E component of the Taft earthquake measuring $0.2 \mathrm{~g}$ with a vibrating time of sec. Fig. 3 shows the analytical model of the scaled frame, which is in accordance with the modelling approach chosen in this study. The analysis of this model has been performed in OpenSees finite element software (Jeon et al., 2012). As shown in Fig. 4, the time-history displacement is in good agreement with the laboratory results.

Fig. 5 shows the modelling performed on OpenSees software in this research, in which the nonlinear behavior of beams, columns, beam-column joints is simulated. For columns and beams, the nonlinear behavior of materials and geometry like the P-delta effect (the P-delta effect is taken into account when introducing the geometrical transformation) is simulated. Columns are modelled using displacement-based-control beam-column fiber elements in areas with the potential to create a plastic hinge at the two ends of the column and an elastic element in the middle of the column. The beams are modelled using a force-based-control beam-column element 
consisting of a length of the nonlinear plastic hinge at two ends of the beam and an elastic element in the middle of the beam (Jeon et al., 2015b). According to Berry et al. (2008) in beams and columns, the plastic hinge length is considered to be half of the depth of the member (Berry et al., 2008). The concrete and reinforced steel fiber models are simulated with the one-dimensional stress-strain response using the existing Concrete01 and Steel02 materials in OpenSees.

The envelope curve for the shear stress-strain relation at joints (Jeon et al., 2015a) is illustrated in Fig. 6.

The beam-column joint is modelled using a zero-length torsional spring with Pinching 4 material existing in the OpenSees. The parameters used in this material is defined based on the work of (Jeon et al., 2015b).

In this modelling, the uncertainties in the materials' strengths and damping ratio are not considered and may be a subject for future researches. Because it is believed that the uncertainties related to earth movements compensate for the effect of not considering other uncertainties (Han et al., 2015).

Structural damage due to the mainshock

The level of damage of the 3-story and 6-story structures were determined based on the value of the increase of the fundamental period $\left(\Delta \mathrm{T}_{1}\right)$ to take into account the effect of structural degradation when exposed to aftershocks. The level of damage is selected in line with one of the high levels of the period of damaged buildings in the 2011 Lorca earthquake that damaged 1- to 4-degree damage at the European macroseismic scale (EMS) (Vidal et al., 2014). Using the $\Delta \mathrm{T}_{1}$ range is advantageous because the fundamental period of the building can be calculated using the tool immediately after the mainshock. With remote control and in real time, the status of the building can be assessed. These damage states are defined using the results of the nonlinear analyzes used to develop the building fragility curves (Trevlopoulos \& Guéguen, 2016). The difference in the fundamental period of the damaged and intact building relative to the fundamental period of the intact building $\left(\mathrm{T}_{(1, \text { orig) }}\right)$ is used to measure the increase in the fundamental period that is defined as follows (Trevlopoulos \& Guéguen, 2016):

$$
\Delta T_{1}=\frac{T_{1, \text { deg }}-T_{1, \text { orig }}}{\tau_{1, \text { orig }}}
$$

In this study, the failure condition of $\Delta \mathrm{T}_{1}=40 \%$ is taken into account for the damage caused by the mainshock before the aftershocks for the 3- and 6-story frames.

Method and steps of analysis

The incremental dynamic analysis (IDA) is a parametric analysis that has recently emerged in various forms for evaluating the overall performance of structures under seismic loads. This concept was first proposed by Bertero in 1977. Various researchers studied the concept and finally turned it into a general method. This procedure contains subjecting a structural model to several ground motion excitations, each scaled to various levels of intensity. Accordingly, numerous curves of response are produced that are all parameterized versus intensity level (Massumi et al., 2015). In this study, IDA is used to determine the collapse capacity of building models. In this analysis, a series of time-history dynamical analysis is performed using a set of ground movements to observe the impact of record-to-record differences (Vamvatsikos \& Cornell, 2002). Spectral acceleration is used as the intensity of the Earth's motion. The selected records were scaled using the approach of Hossain et al. (2013) (Hossain et al., 2013). The analysis is performed in such a way that the response and structural damage are first recorded in the main record. Then the damaged structure due to the mainshock is exposed to the aftershock movement, which increases in intensity until the structure collapses. structural instability due to hinges formation and mechanism (SI) is used when instability happens in the entire or in a part of the structure due to hinge formation and mechanism. There are four overall instability cases due to structures geometry (Monavari \& Massumi, 2012). This study focuses on the lateral collapse of structures due to global dynamic instability in the form of large engineering demands (story drifts). In the IDA of 62 aftershocks, Table 2 with different properties was used to investigate the impact of aftershocks on the collapse capacity of the frames damaged due to the mainshock. Earthquake number 2 was randomly selected as the mainshock from the 
remote zone record category of FEMA P695. Then two 3- and 6-story RC frames modelled in the OpenSees environment are exposed to a scale of the mainshock record to reach the level of damage considered in Section 3.4. An 8-second interval between the movement of the mainshock and the aftershock was added to simulate the structure reached to rest after the mainshock and to maintain the damage caused by it. In the 12-story building mentioned in the works of Raghunandan et al. (2015), the remaining velocities of 0 to 3 inches per second are observed 4 seconds after the end of the mainshock (Raghunandan et al., 2015). Their research has shown that the remaining velocities around these values do not affect the collapse capacity of the damaged structures. Then all 62 aftershock records for both frames were recorded using IDA and spectral acceleration corresponding to frame collapse. All inconsistencies have been corrected throughout the analysis with continuous monitoring. To investigate the impact of each of the aftershock characteristics on the aftershock collapse capacity, the records are divided into two parts according to the desired characteristic and the fragility curve for each group.

\section{Analysis Results}

This section uses the material presented in the preceding sections and the results of the analysis are found based on that material to develop box plot diagrams and to evaluate the fragility curves of 3-and 6 -story RC frames in the form of diagrams. These diagrams can play an important role in assessing the impact of aftershock characteristics on RC frames. In these curves, the influence of characteristics such as mean period, dominant period, frequency bandwidth, duration and structure of the structures is determined.

\section{Medium period characteristics}

Fig. 7 shows a box plot diagram of the collapse capacity of the 3- and 6-story frames for a group of medium and short periodic collapses. The bottom and top of the box plot show the $25^{\text {th }}$ and $75^{\text {th }}$ percentiles and the middle bar of the box plot shows the middle value. The bottom of the whiskers on this chart shows the $2^{\text {nd }}$ and $98^{\text {th }}$ percentiles. The shown points in the graph also correspond to outliers. As can be seen in the plots of the 3 -story frame, the $2^{\text {nd }}, 25^{\text {th }}$ percentiles and the median value of the larger mean period group are lower than the corresponding values in the smaller mean period group. This indicates a lower collapse capacity of this group of intermediate periods. In the plots of 6-story, all percentages for the larger medium period group show lower collapse capacity for this medium period group.

Fig. 8 illustrates the relationship between the spectral acceleration of the first mode of 3- and 6- story structures with a $5 \%$ damping and the probability of collapse of the mainshock-damaged structure for the characteristic medium period. According to these graphs, the probability of collapse of 3- and 6-story structures for intermediate periods of more than 0.5 seconds for a fixed spectral acceleration is generally increased. The collapse of the 6-story structure is more likely for both groups of intermediate periods than the 3-story structure.

\section{Characteristic of the predominant velocity period}

Fig. 9 shows a box plot diagram of the collapse capacity of the 3- and 6-story frames for predominant velocity periods less than or greater than the fundamental period $\left(T_{1}\right)$ of buildings. As can be seen in the 
plots of 3-story, all percentiles of the dominant period group are less than $T_{1}$, indicating a lower collapse capacity of this dominant period group. This figure also shows the box plots diagram mentioned for the 6-story frame, which is similar to the 3-story frame. But the overall collapsed capacity of the 6-story frame is less than the 3-story frame.

Fig. 10 shows the relationship between the spectral acceleration of the first mode 3-and 6-story structures with a $5 \%$ damping and the probability of collapse of the mainshock-damaged structure for the dominant period characteristic. Similar to the results for the intermediate period, the probability of collapse of 3- and 6-story structures for dominant periods larger than the fundamental period for a constant spectral acceleration is generally increased. In both structures for the two groups of dominant periods, the difference in the obtained fragility curves is much greater than the corresponding graphs for the mean period too. Besides, similar to the average period, the overall probability of collapse of the 6story structure is generally higher than the 3-story structure at a constant acceleration.

\section{Frequency bandwidth characteristic}

Fig. 11 shows a box plot diagram of the collapsed capacity of the 3-and 6-story frames for bandwidths less than and greater than 0.5 . As can be seen in the plots of the 3-story frame, the percentages for the bandwidth group are greater than 0.5 , indicates a higher collapse capacity of this bandwidth. Plot diagrams mentioned for the 6-story frame are similar to those of the 3-story frame. In the 6-story frame, the percentiles of the two bandwidths are closer than the values for the 3-story frame.

Fig. 12 shows the relationship between the spectral acceleration of the first mode of the 3-and 6-story structures with $5 \%$ damping and the probability of collapse of the mainshock-damaged structure for frequency bandwidths less than 0.5 . These graphs are roughly in line with the graphs obtained for the dominant period characteristic. The reason for this may be that both properties are obtained using the elastic velocity spectra of the structures. So the same descriptions of Section 4.2 apply here. From the similarity of the diagrams obtained for the dominant period and frequency bandwidth, it can be concluded that using these characteristics to develop fragility curves with good approximation yields similar results.

\section{Characteristics of the effective time of aftershock}

Fig. 13 shows the box plot diagram of the collapse capacity of the 3 and 6-story frames for periods of less than 11 seconds. As can be seen in the plots of the 3-story frame, the percentages for the group times less than 11 seconds, are indicating a lower collapse capacity of this group than the effective times. Also, the plots of the 6-story frame are similar to those of the 3-story frame. However, due to the lower collapse capacity of this frame, the difference of the corresponding percentiles was obtained compared to the three-story frame.

Fig. 14 shows the relationship between the spectral acceleration of the first 3- and 6-story structures with a $5 \%$ damping and the probability of collapse of the mainshock damaged structure for an effective 
duration of fewer than 11 seconds. The diagram of the 3-story structure shows that the probability of collapse of the structure is more than 11 seconds for the aftershock group. But in the curve of the 6-story structure, the two curves are almost identical.

\section{Site characteristics}

Fig. 15 illustrates the box plot diagrams of the collapse capacity of the 3-and 6-story frames for different sites. As can be seen, the percentages for Italy and Chichi Taiwan record sets are lower, indicating a lower collapse capacity of this group of sites.

Fig. 16 shows the relationship between the spectral acceleration of the first 3- and 6-story structures with a $5 \%$ damping and the probability of collapse of the mainshock-damaged structures for the California, Italy, and Chichi Taiwanese sites. The diagram for the 3-story building shows that the probability of structures collapsing at the California site is much lower than at the Italy and Chichi sites. While these curves are slightly different for the Italy and Chichi sites. Similar results can be seen in the graph for the 6-story structure. However, the fragility is generally higher than that of the three-story structure. Besides, in this graph, the curve of the Chichi structure is in a higher position than the other curves.

\section{Validation of the results}

According to the work of Sang et al. (2014) who investigated the effect of the mean period characteristic and the effective time of aftershock on the collapse capacity of a steel frame, they concluded that the collapse capacity of the structure decreases with increasing Tm and Ds (Song et al., 2014). The results obtained by them justify the results obtained in Sections 4.1 and 4.4 of this paper. Since the curves for the dominant period and bandwidth are also related to the frequency content of the ground motion, the results obtained in those graphs with respect to the characteristic of the average period are reasonable. Hosseinpour and Abdul Nabi (2017) showed that the earthquake zone in question had a significant impact on the fragility curves of RC frames with different classes (Hosseinpour \& Abdelnaby, 2017). They also observed that the difference in fragility curves decreased with the increase in the number of stories, which could be due to the movement of upper stories in tall buildings under a single vibration. In this study, similar results were obtained with respect to this difference in curves. In Section 4.5 of this paper, the significant effect of the seismic site on the fragility curve is observed.

\section{Discussion of results}

Diagrams and curves related to the aftershock characteristics for two 3- and 6-story frames were investigated. It was observed that the collapse capacity of the frames decreases with increasing Tm and $\mathrm{Tg}$, which may be due to a significant increase in the response of structures with a tendency for the frequency content of aftershock records to be the dominant period. From the similarity of the graphs obtained for the dominant period and frequency bandwidth, it can be concluded that the use of one of these characteristics is sufficient to develop the curves. Also, using the dominant period or frequency bandwidth, compared to the average period, higher curves are obtained, especially for the 3-story frame. 
According to the results observed on the 3-story frame, the probability of collapsing of the structure for periods of more than 11 seconds is higher. Given the decreasing characteristics considered in the structural system and the direct relationship between the aftershocks and loading periods, the possibility of structural collapse at higher times is justified. But the fragility curve obtained for the 6-story frame shows the effect of effective duration. This may be due to the early collapse of the 6-story structure compared to the 3-story structure due to its early fragility due to the higher impact of disregarding seismic requirements than the 3-story frame. The obtained results show that the frames in different constructions have different capacities. The low likelihood of collapse in aftershocks in California indicates that the frequency content and effective duration of the site are different from those estimated elsewhere. This result may be due to different mechanisms of ground movements occurring in different structures and generating different characteristics.

\section{Conclusions}

The significant effect of frequency content and duration of time and site effects of aftershocks on the fragility curves of damaged frames and corresponding box plot diagrams was investigated. It can be concluded that if random aftershocks combined with mainshocks are used for seismic evaluation of structures, the probability of collapse of the damaged structure due to mainshocks may be much higher than the actual value. Besides, if the aftershock used has a shorter duration and higher frequency than expected, the possibility of collapsing of the structure can be estimated too low. Therefore, it is necessary to consider the characteristics of aftershocks as an important issue in the procedure of selecting records for the generation of seismic sequences.

\section{Declarations}

Ethical statements (The developed method is the original effort of the authors which is not submitted or published elsewhere)

Funding (This research was not funded by any funding bodies)

Conflict of interest/Competing interests (The Authors declare that they have no conflict of interest)

Availability of data and material (Data and material are available)

Code availability (The developed codes are available)

Plant reproducibility (Not applicable)

Clinical trials registration (Not applicable)

Gels and bolts/ Image manipulation (Not applicable)

High-risk content (Not applicable) 


\section{References}

Abdelnaby, A. E. (2018). Fragility curves for RC frames subjected to Tohoku mainshock-aftershocks sequences. Journal of Earthquake Engineering, 22(5), 902-920. doi:

https://doi.org/10.1080/13632469.2016.1264328

Berry, M. P., Lehman, D. E., \& Lowes, L. N. (2008). Lumped-plasticity models for performance simulation of bridge columns. ACI Structural Journal, 105(3), 270.

Bommer, J. J., Hancock, J., \& Alarcón, J. E. (2006). Correlations between duration and number of effective cycles of earthquake ground motion. Soil Dynamics and Earthquake Engineering, 26(1), 1-13. doi: https://doi.org/10.1016/j.soildyn.2005.10.004

Bracci, J. M., Reinhorn, A. M., \& Mander, J. B. (1995). Seismic resistance of reinforced concrete frame structures designed for gravity loads: performance of structural system. Structural Journal, 92(5), 597609.

Bray, J. D. (2007). Simplified seismic slope displacement procedures Earthquake geotechnical engineering (pp. 327-353): Springer.

Chakraborti, A., \& Gupta, V. K. (2005). Scaling of strength reduction factors for degrading elasto-plastic oscillators. Earthquake Engineering \& Structural Dynamics, 34(2), 189-206. doi:

https://doi.org/10.1002/eqe.416

Green, R. A., \& Terri, G. A. (2005). Number of equivalent cycles concept for liquefaction evaluationsRevisited. Journal of Geotechnical and Geoenvironmental Engineering, 131(4), 477-488. doi: https://doi.org/10.1061/(ASCE)1090-0241(2005)131:4(477)

Han, R., Li, Y., \& van de Lindt, J. (2015). Assessment of seismic performance of buildings with incorporation of aftershocks. Journal of Performance of Constructed Facilities, 29(3), 04014088. doi: https://doi.org/10.1061/(ASCE)CF.1943-5509.0000596

Hancock, J., \& Bommer, J. J. (2006). A state-of-knowledge review of the influence of strong-motion duration on structural damage. Earthquake Spectra, 22(3), 827-845. doi: https://doi.org/10.1193/1.2220576

Hossain, M. R., Ashraf, M., \& Padgett, J. E. (2013). Risk-based seismic performance assessment of Yielding Shear Panel Device. Engineering Structures, 56, 1570-1579. doi: https://doi.org/10.1016/j.engstruct.2013.07.032

Hosseinpour, F., \& Abdelnaby, A. (2017). Fragility curves for RC frames under multiple earthquakes. Soil Dynamics and Earthquake Engineering, 98, 222-234. doi: https://doi.org/10.1016/j.soildyn.2017.04.013 
Imashi, N., \& Massumi, A. (2011). A comparative study of the seismic provisions of Iranian seismic code (standard no. 2800) and international building code 2003.

Jeon, J.-S., Lowes, L. N., DesRoches, R., \& Brilakis, I. (2015a). Fragility curves for non-ductile reinforced concrete frames that exhibit different component response mechanisms. Engineering Structures, 85, 127143. doi: https://doi.org/10.1016/j.engstruct.2014.12.009

Jeon, J. S., DesRoches, R., Lowes, L. N., \& Brilakis, I. (2015b). Framework of aftershock fragility assessment-case studies: older California reinforced concrete building frames. Earthquake Engineering \& Structural Dynamics, 44(15), 2617-2636. doi: https://doi.org/10.1002/eqe.2599

Jeon, J., DesRoches, R., Brilakis, I., \& Lowes, L. (2012). Aftershock fragility curves for damaged nonductile reinforced concrete buildings. Paper presented at the 15th World Conference on Earthquake Engineering.

Kumar, M., Castro, J., Stafford, P., \& Elghazouli, A. (2011). Influence of the mean period of ground motion on the inelastic dynamic response of single and multi degree of freedom systems. Earthquake Engineering \& Structural Dynamics, 4O(3), 237-256. doi: https://doi.org/10.1002/eqe.1013

Kumar, M., Stafford, P. J., \& Elghazouli, A. Y. (2013). Influence of ground motion characteristics on drift demands in steel moment frames designed to Eurocode 8. Engineering Structures, 52, 502-517. doi: https://doi.org/10.1016/j.engstruct.2013.03.010

Massumi, A., Mahboubi, B., \& Ameri, M. R. (2015). Seismic response of RC frame structures strengthened by reinforced masonry infill panels. Earthquakes and Structures, 8(6), 1435-1452. doi:

http://dx.doi.org/10.12989/eas.2015.8.6.1435

Monavari, B., \& Massumi, A. (2012). Estimating displacement demand in reinforced concrete frames using some failure criteria. International Journal of Advanced Structural Engineering, 4(1), 1-6. doi: https://doi.org/10.1186/2008-6695-4-4

Raghunandan, M., \& Liel, A. B. (2013). Effect of ground motion duration on earthquake-induced structural collapse. Structural Safety, 41, 119-133. doi: https://doi.org/10.1016/j.strusafe.2012.12.002

Raghunandan, M., Liel, A. B., \& Luco, N. (2015). Aftershock collapse vulnerability assessment of reinforced concrete frame structures. Earthquake Engineering \& Structural Dynamics, 44(3), 419-439. doi: https://doi.org/10.1002/eqe.2478

Rathje, E. M., Abrahamson, N. A., \& Bray, J. D. (1998). Simplified frequency content estimates of earthquake ground motions. Journal of Geotechnical and Geoenvironmental Engineering, 124(2), $150-$ 159. doi: https://doi.org/10.1061/(ASCE)1090-0241(1998)124:2(150)

Ruiz-García, J. (2012). Mainshock-aftershock ground motion features and their influence in building's seismic response. Journal of Earthquake Engineering, 16(5), 719-737. doi: 
Ruiz-García, J., \& Miranda, E. (2004). Inelastic displacement ratios for design of structures on soft soils sites. Journal of Structural Engineering, 130(12), 2051-2061. doi: https://doi.org/10.1061/(ASCE)07339445(2004)130:12(2051)

Ryu, H., Luco, N., Uma, S., \& Liel, A. (2011). Developing fragilities for mainshock-damaged structures through incremental dynamic analysis. Paper presented at the Ninth pacific conference on earthquake engineering, Auckland, New Zealand.

Song, R., Li, Y., \& van de Lindt, J. W. (2014). Impact of earthquake ground motion characteristics on collapse risk of post-mainshock buildings considering aftershocks. Engineering Structures, 81, 349-361. doi: https://doi.org/10.1016/j.engstruct.2014.09.047

Trevlopoulos, K., \& Guéguen, P. (2016). Period elongation-based framework for operative assessment of the variation of seismic vulnerability of reinforced concrete buildings during aftershock sequences. Soil Dynamics and Earthquake Engineering, 84, 224-237. doi: https://doi.org/10.1016/j.soildyn.2016.02.009

Uang, C.-M., \& Maarouf, A. (1994). Deflection amplification factor for seismic design provisions. Journal of Structural Engineering, 120(8), 2423-2436. doi: https://doi.org/10.1061/(ASCE)07339445(1994)120:8(2423)

Vamvatsikos, D., \& Cornell, C. A. (2002). Incremental dynamic analysis. Earthquake Engineering \& Structural Dynamics, 31(3), 491-514. doi: https://doi.org/10.1002/eqe.141

Vidal, F., Navarro, M., Aranda, C., \& Enomoto, T. (2014). Changes in dynamic characteristics of Lorca RC buildings from pre-and post-earthquake ambient vibration data. Bulletin of Earthquake Engineering, 12(5), 2095-2110. doi: https://doi.org/10.1007/s10518-013-9489-5

\section{Figures}




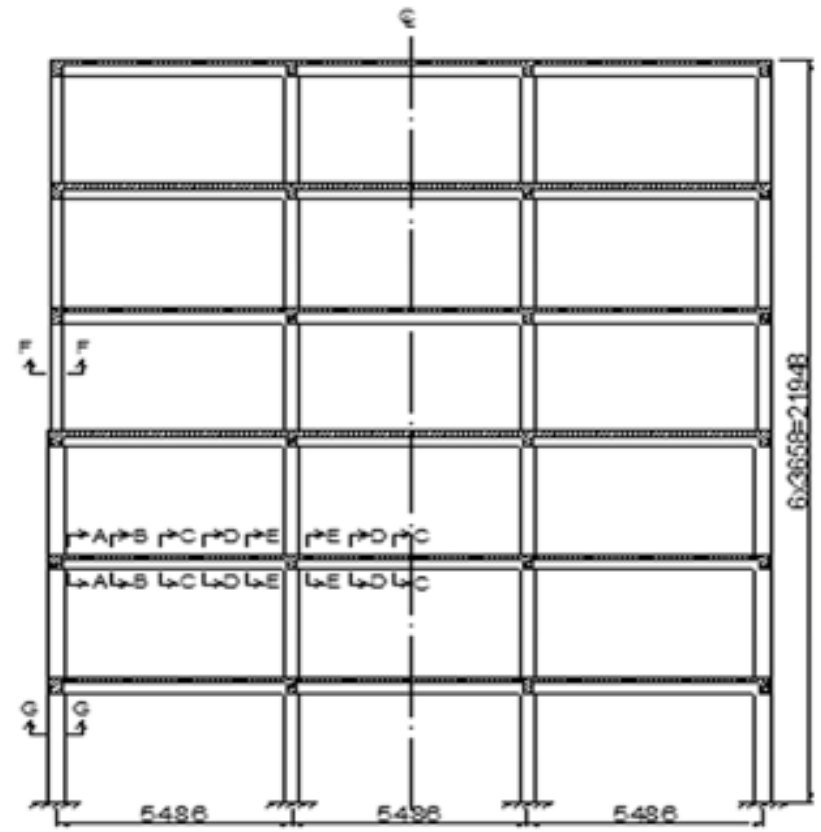

Figure 1

6-story building frame (Han et al., 2015)
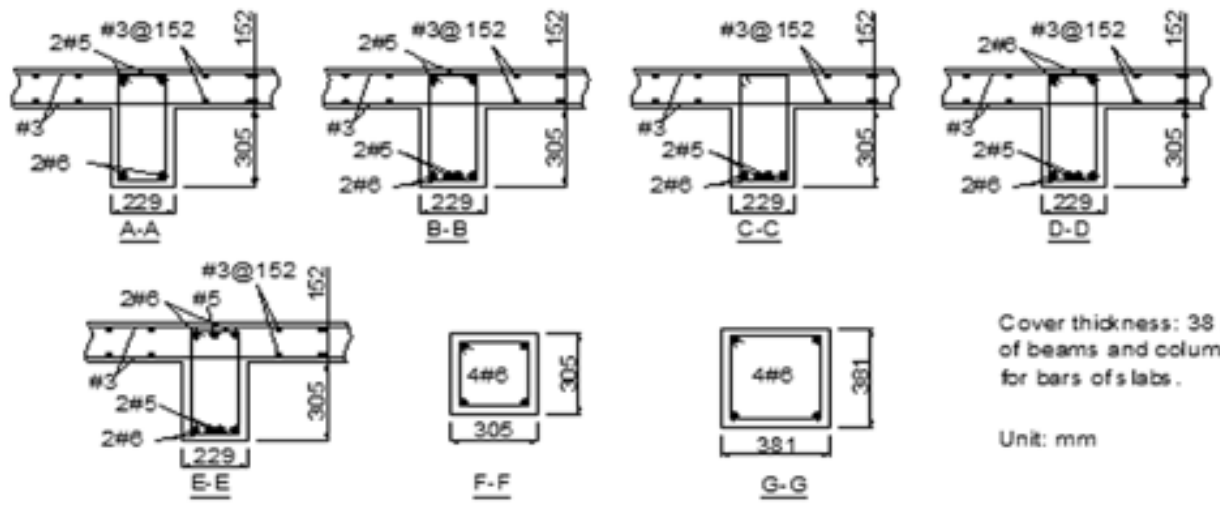

Cover thidkness: $38 \mathrm{~mm}$ for bars of beams and columns. $19 \mathrm{~mm}$ for bars of 3 labs.

Unit: mm

\section{Figure 2}

Reinforcements' details (Han et al., 2015)
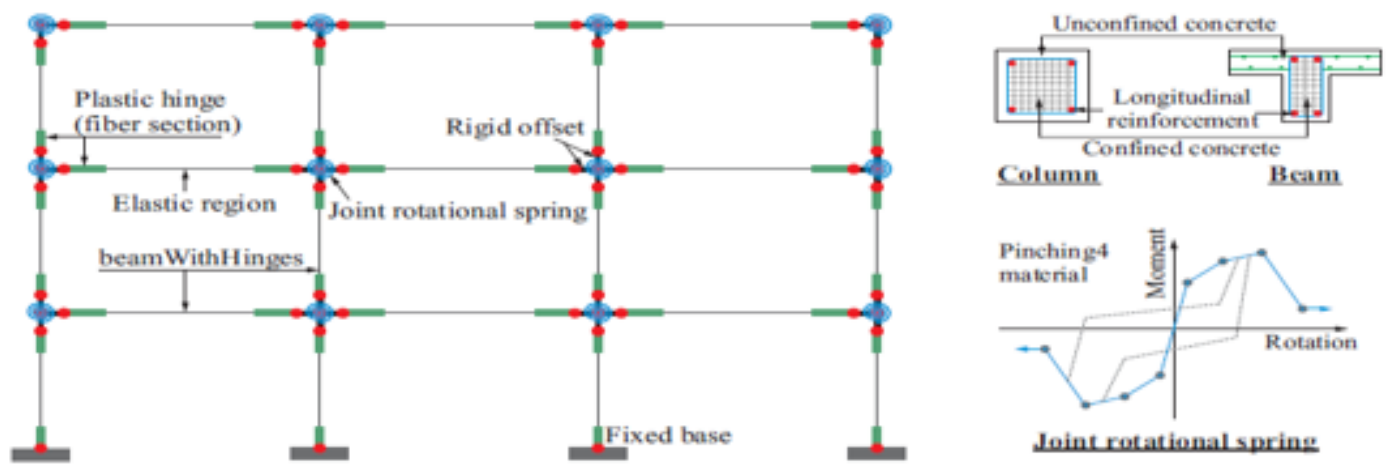
Figure 3

Scaled Frame Analytical Model (Jeon et al., 2012)

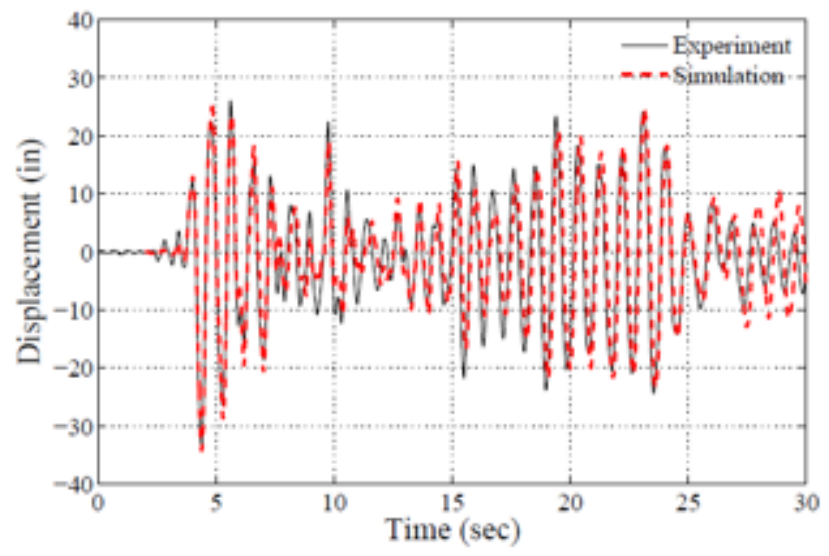

Figure 4

Comparison of the results of the laboratory time-history response of Bracci et al. (1995) and the results of the analysis by the software (Bracci et al., 1995; Jeon et al., 2012).

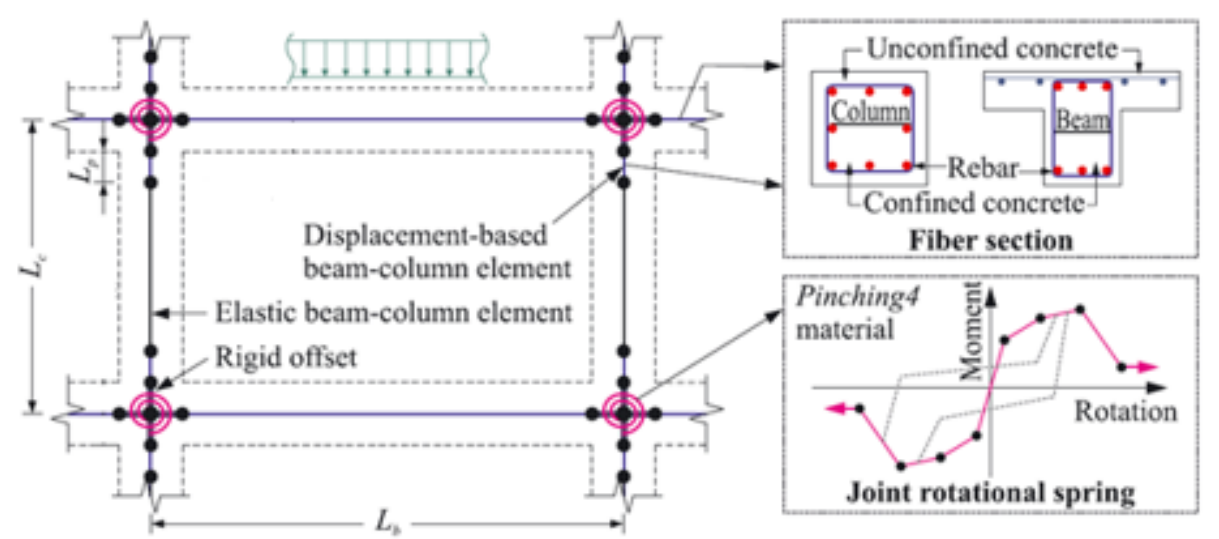

Figure 5

Frame analytical model (Jeon et al., 2015b)

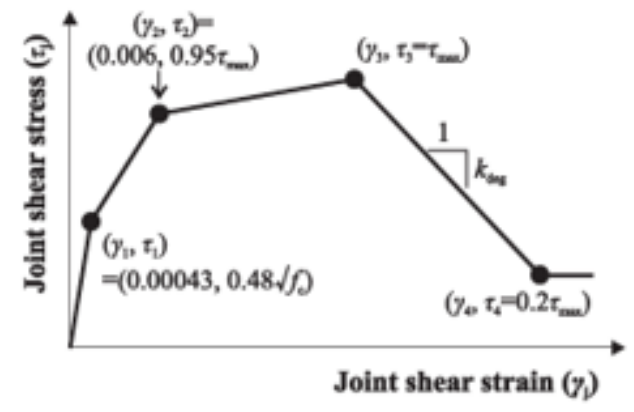

Figure 6 
Envelope curve for the shear stress-strain relation at joints (Jeon et al., 2015a)

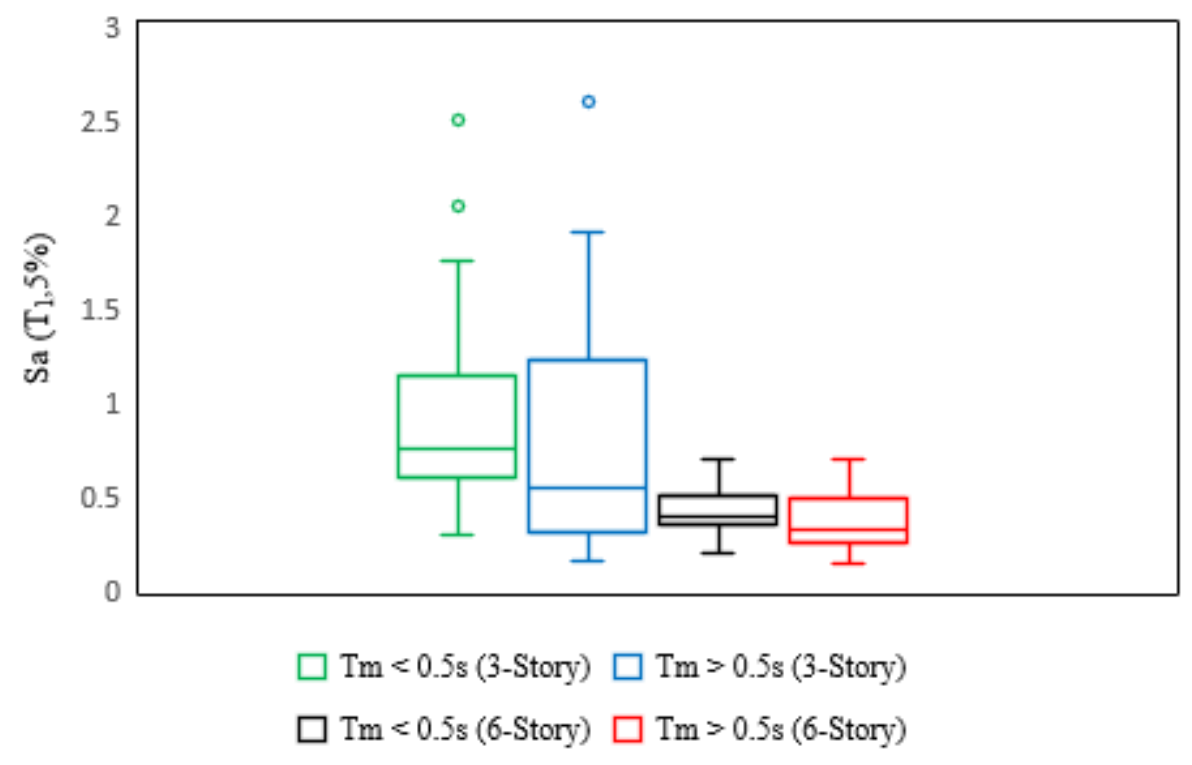

Figure 7

Box plot diagram of the collapse capacity of the 3- and 6-story frames for short and long periods

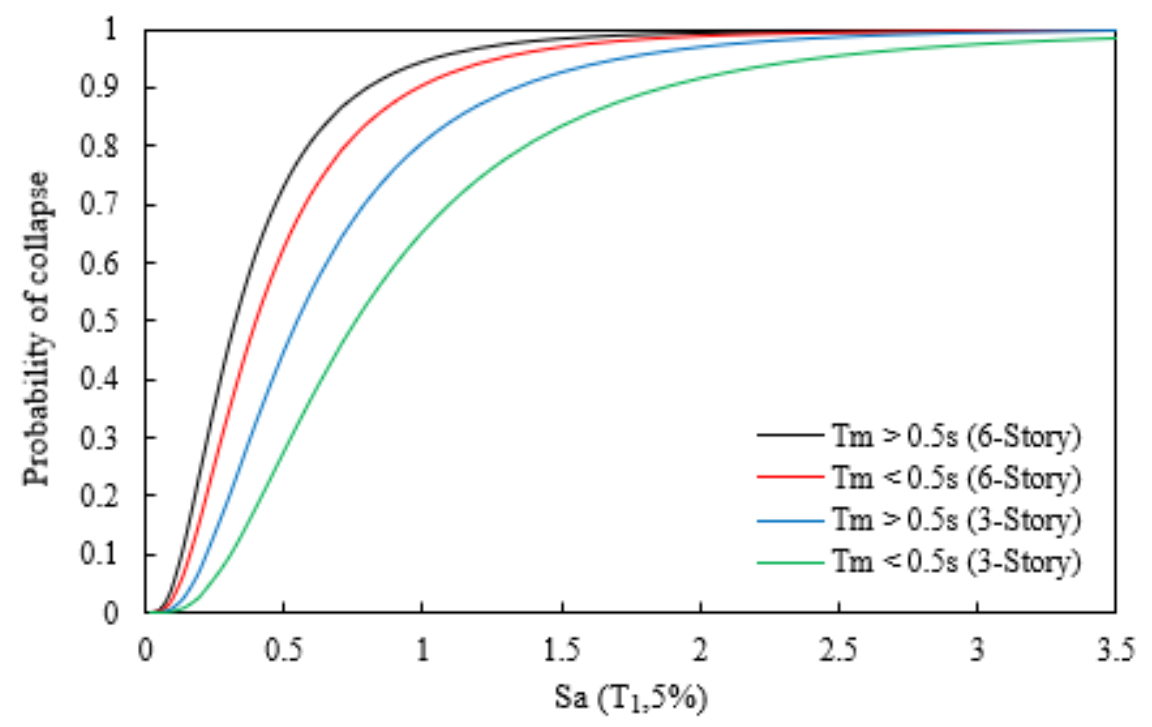

Figure 8

Fragility curve of 3- and 6-story frames for short and long periods 


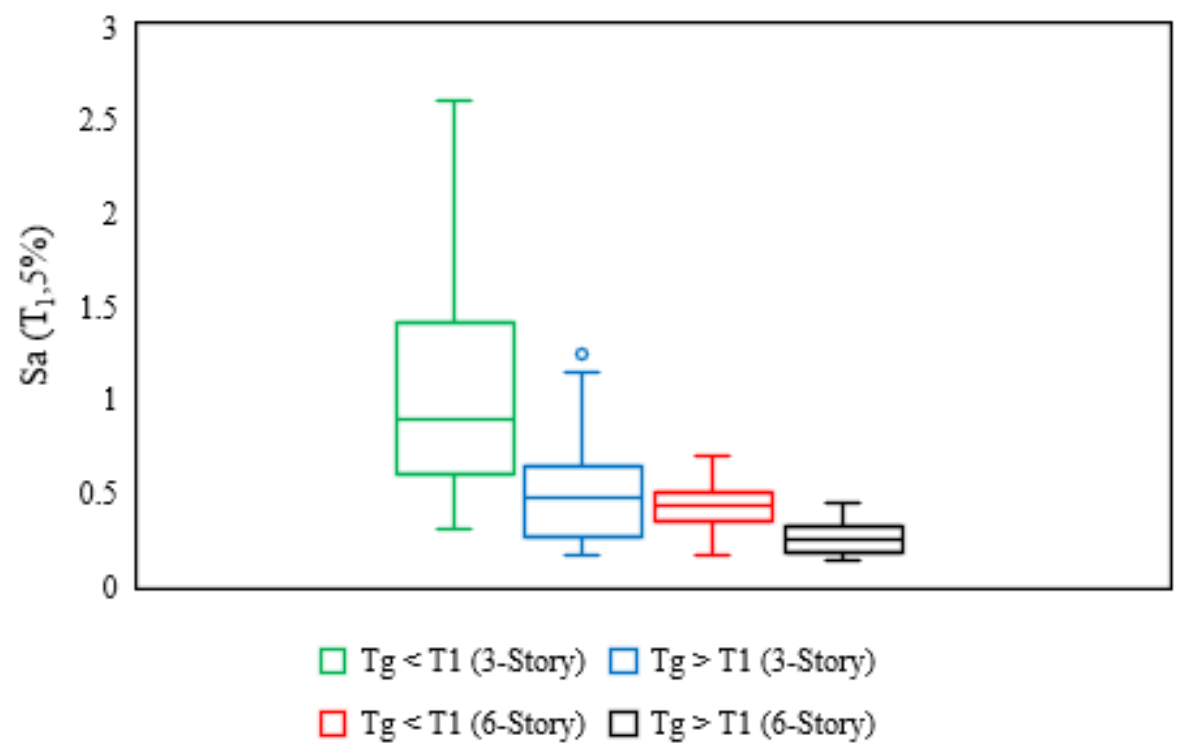

Figure 9

Box plot diagram of the collapsed capacity of 3- and 6-story frames for dominant periods greater or smaller than $\mathrm{T} 1$

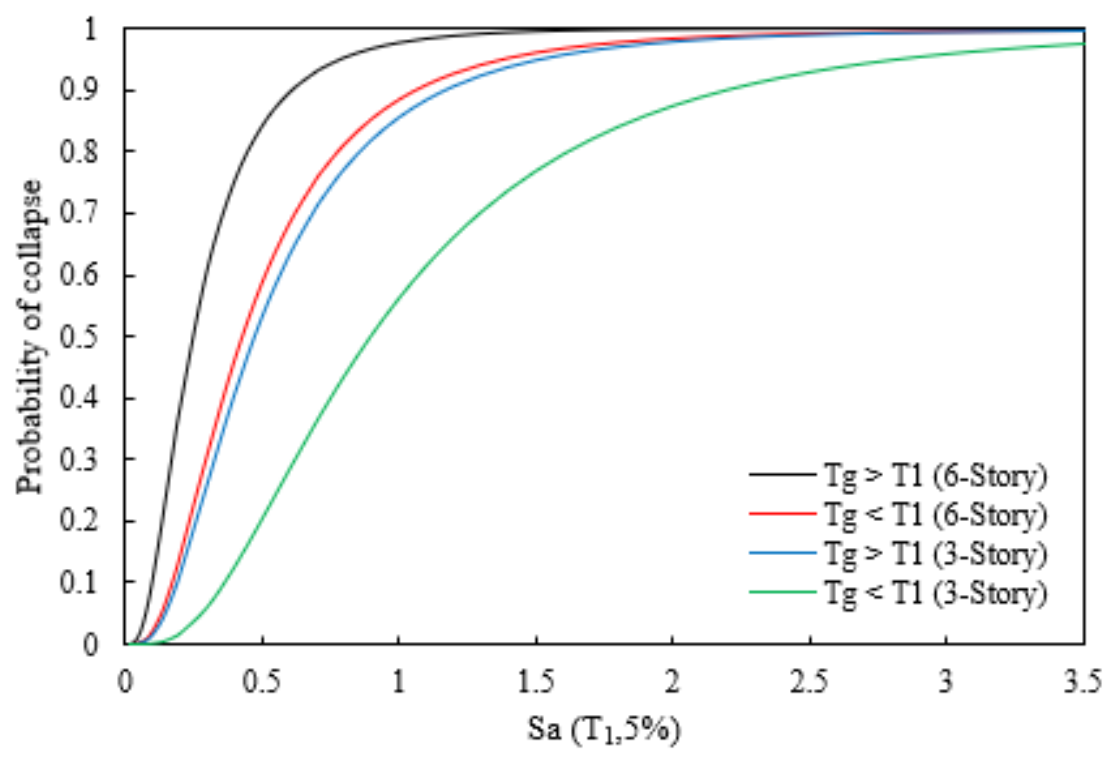

Figure 10

Fragility curve of the 3-and 6-story frames for short and long dominant periods 


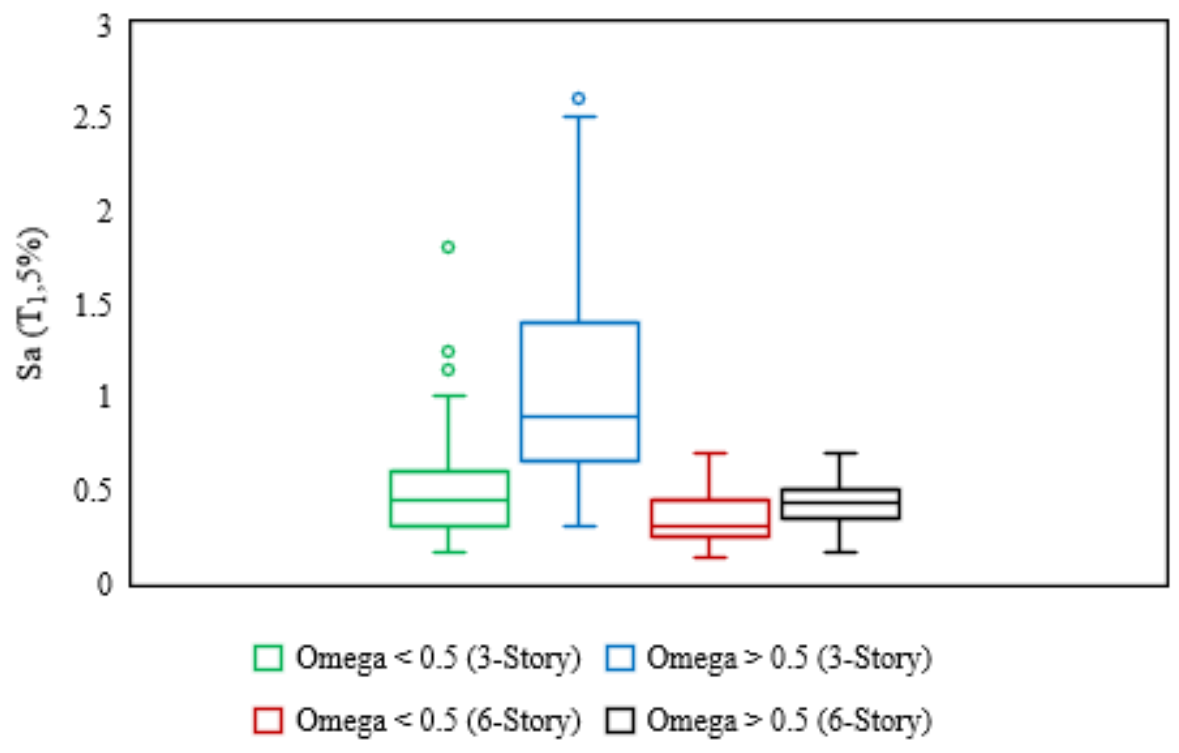

\section{Figure 11}

Box plot diagram of the collapsed capacity of the 3- and 6-story frames for dominant periods smaller and greater than 0.5

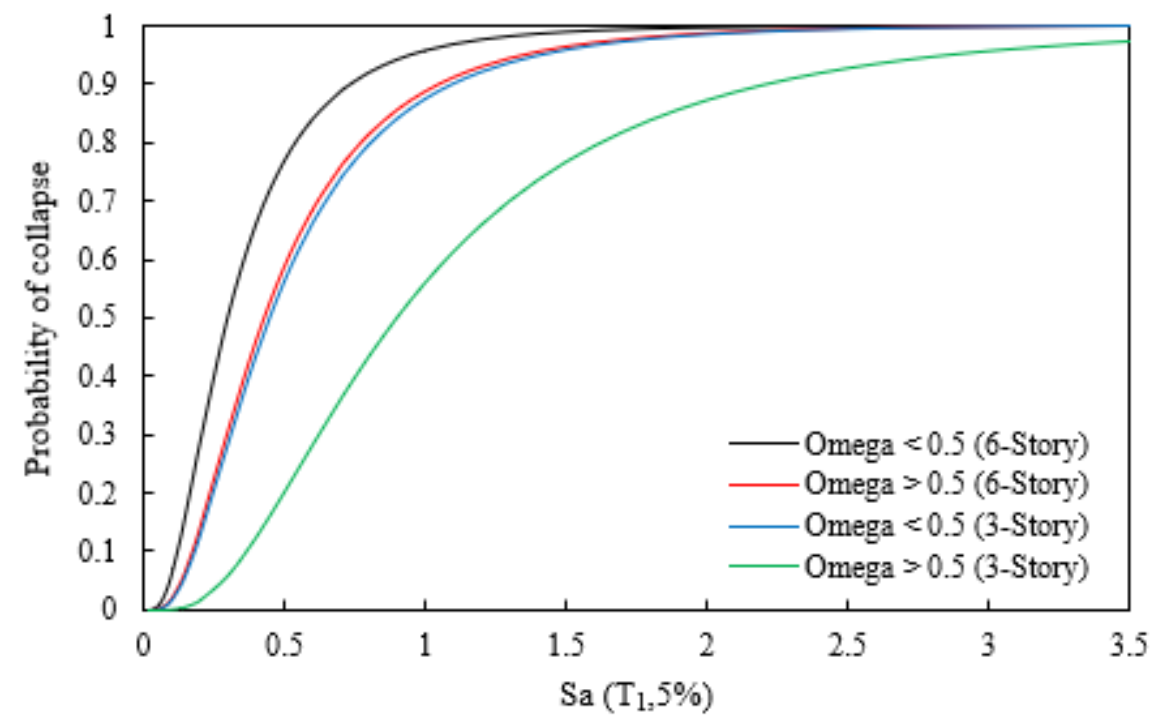

Figure 12

Fragility curve of the 3- and 6-story frames for the frequency bandwidth smaller and greater than 0.5 


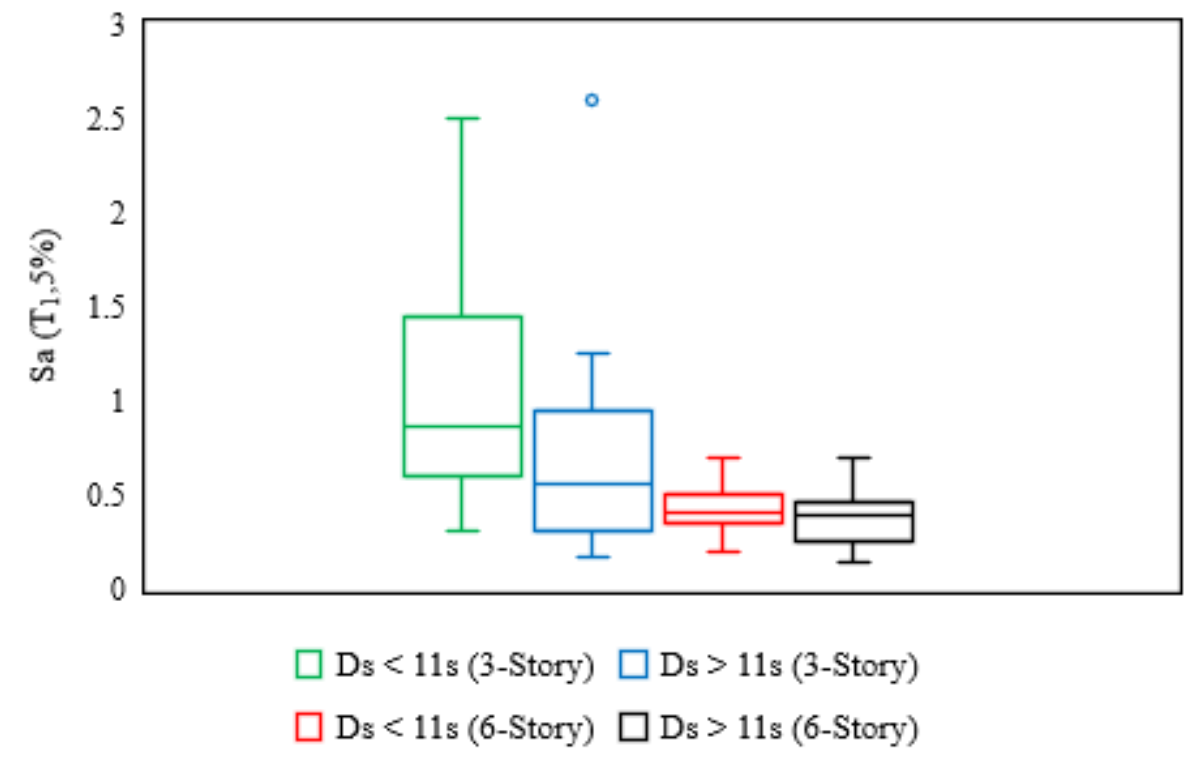

Figure 13

Box plot diagram of the collapsed capacity of the 3- and 6-story frames for the significant duration of the earth movement smaller and greater than 11 seconds

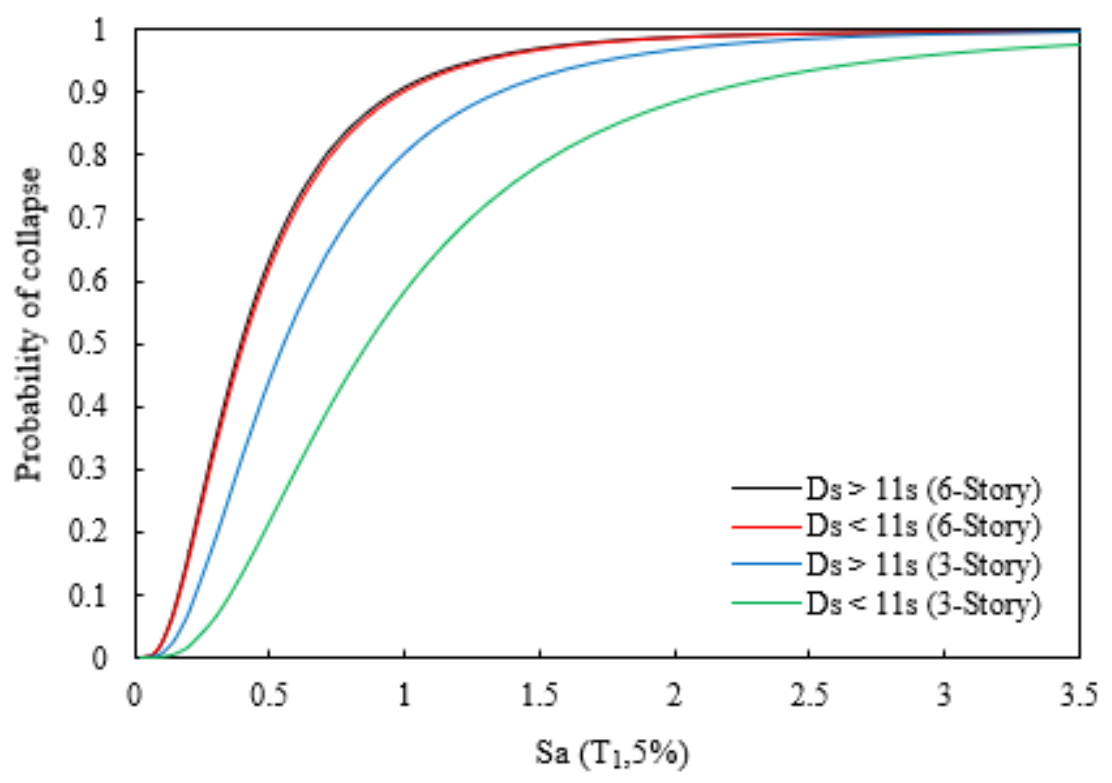

Figure 14

Fragility curve of the 3-and 6-story frames for the significant duration of the earth movement smaller and greater than 11 seconds 


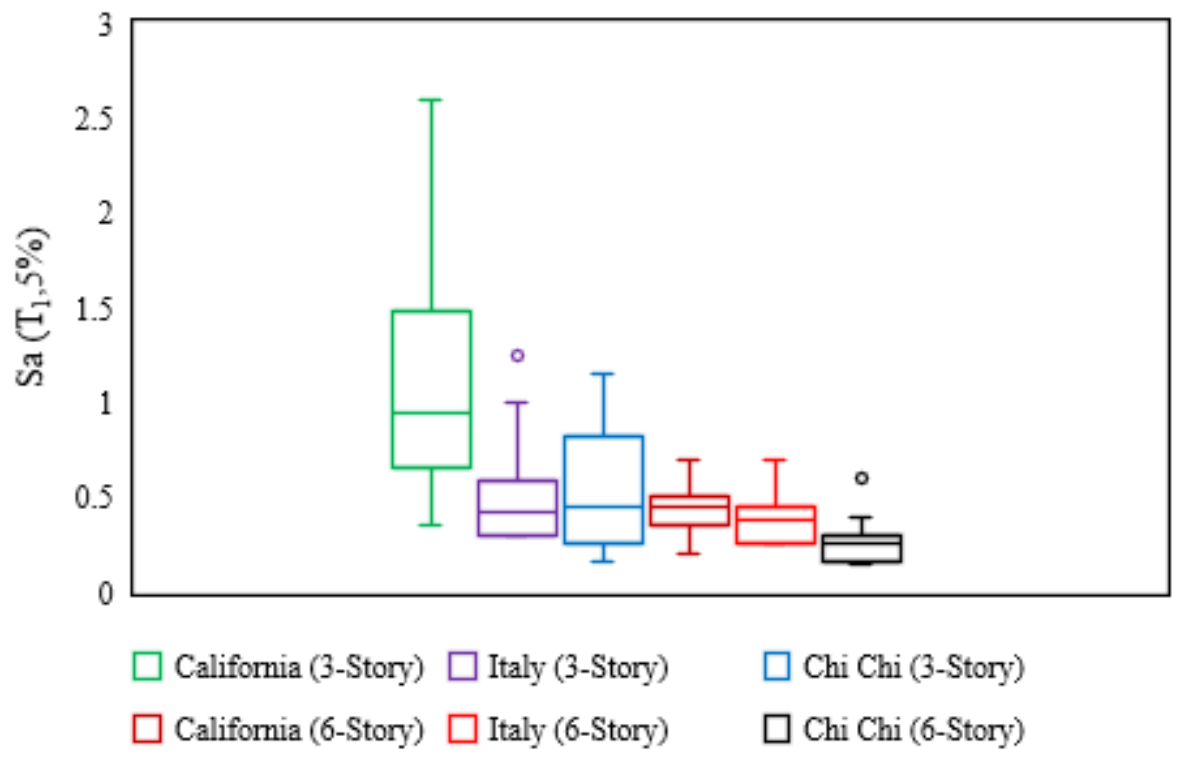

Figure 15

Box plot diagrams of the collapse capacity of the 3- and 6-story frames for different sites.

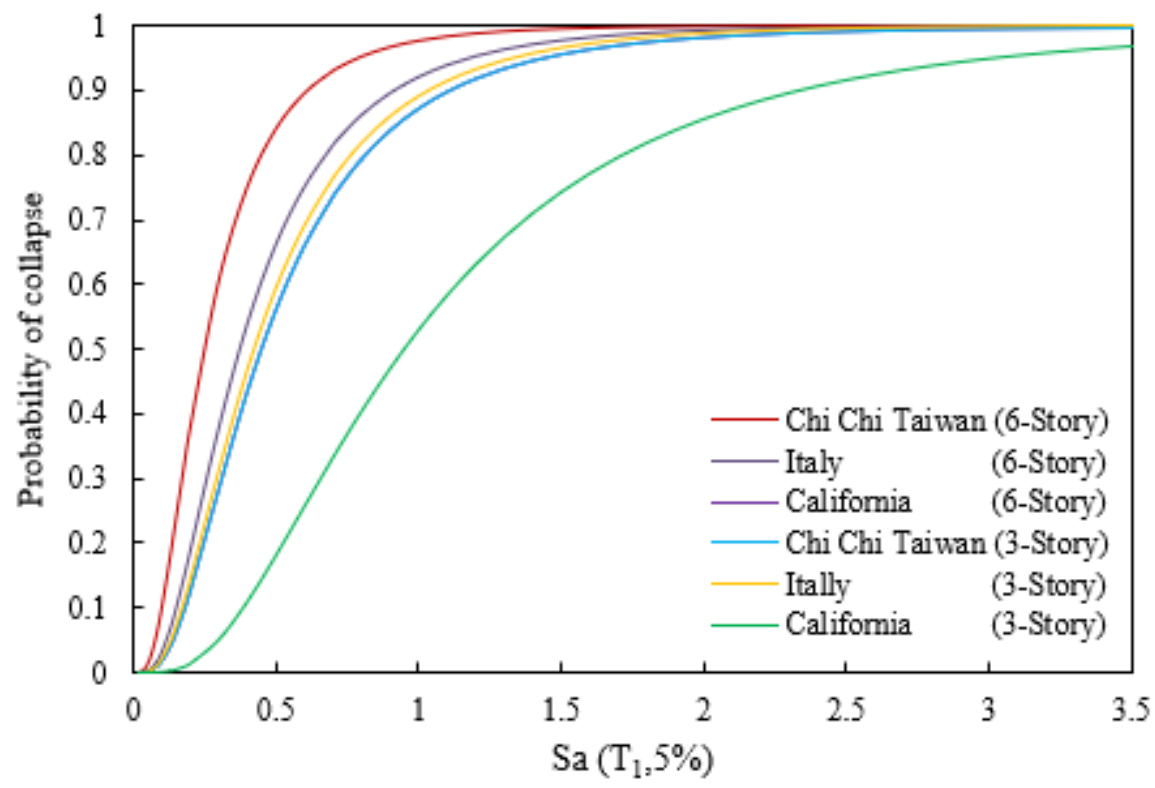

Figure 16

Fragility curve of the 3- and 6-story frames for different sites (diagrams for 3-story of Chichi site and 6story of California site coincide with each other). 